\title{
The science and ethics of extinction
}

To the Editor - Objectivity is one of the defining features of scientific research. But to what extent should scientists also discuss the ethical implications of their work - is this even 'part of our job'? Researchers in the natural sciences receive little or no ethics training, and broad dialogues on ethics are rarely given precedence. So how should we approach the boundary between science and ethics, where what we say may have far-reaching, real-life consequences?

Late last year, the Washington Post published a perspective piece titled 'We don't need to save endangered species. Extinction is part of evolution' ${ }^{\text {'. The author }}$ argued that because threatened species will die out anyway, there is no point in feeling guilty, nor in investing substantial resources in conserving biodiversity. After all, extinct species will be replaced by evolution. However, the piece was quickly criticized on evolutionary ${ }^{2,3}$, moral $^{3,4}$ and rhetorical ${ }^{5}$ grounds.

We organized a joint response to that article $^{6}$. In addition to collecting signatures, we encouraged open feedback in a collaborative document. As the text grew, it became apparent that while we were unified in our opposition to the position expressed in the piece, a major point of divide was whether our response should be based on scientific or ethical arguments - or both.

Some people felt that scientists should stick to factual evidence to maintain public credibility: it is unscientific to wade into ethical arguments. The article could be refuted on measurable (although sometimes complex or ambiguous) evidence that biodiversity is essential for sustaining society ${ }^{7}$. This includes the role of species in food production, shelter, clothing, clean water, disease regulation, soil protection and ecosystem functioning ${ }^{8,9}$, as well as yet-unknown functions from the large number of species that remain to be described and studied ${ }^{10}$.
Other co-signatories, however, felt strongly that ethics constituted the primary flaw in the original article, and that ethical considerations are critical for the conservation of biodiversity. Morality is more subjective than the natural sciences, yet this does not mean we should neglect its importance. Moreover, moral argumentation can be evaluated on the basis of logical consistency and the plausibility of the principles to which it appeals.

There is much to say for the moral view that biodiversity should be protected not only for its value for humans, but also for its intrinsic worth.

We feel that both angles are appropriate and required. They should be independently framed and communicated, but refer to each other often. The ethics of extinction and values of biodiversity are not new topics ${ }^{11,12}$, and more work to understand these aspects is underway by agencies, institutions and individuals around the world, including the Intergovernmental Science-Policy Platform on Biodiversity and Ecosystem Services?.

If we as biologists are not vocal about our values, we risk being poorly prepared to combat major societal challenges including the ongoing sixth mass extinction on the planet. This is particularly crucial in a time when strong financial and political interests undermine the values of biodiversity. Decision-makers need contextual interpretations, not just raw data.

The debate we witnessed highlights the need for a deeper and broader discussion on how and when to incorporate ethical interpretations into our scientific work. In the case of biodiversity conservation, this issue has not received as much attention as it requires.

We urge scientists to reflect on their own positions and discuss both ethical and evidence-based values of biodiversity with colleagues, relatives and society. Then we need to voice all valid arguments towards the goal of protecting the future of biodiversity. This, we argue, is absolutely part of our job.

\author{
Alexandre Antonelli ${ }^{1,2,3,4 *}$ and \\ Allison Perrigo ${ }^{1,2 \star}$ \\ ${ }^{1}$ Gothenburg Global Biodiversity Centre, \\ Gothenburg, Sweden. ${ }^{2}$ Department of Biological and \\ Environmental Sciences, University of Gothenburg, \\ Gothenburg, Sweden. ${ }^{3}$ Gothenburg Botanical Garden, \\ Gothenburg, Sweden. ${ }^{4}$ Department of Organismic \\ and Evolutionary Biology, Harvard University, \\ Cambridge, MA, USA. \\ ${ }^{*}$-mail: alexandre.antonelli@bioenv.gu.se; \\ allison.perrigo@bioenv.gu.se
}

Published online: 26 February 2018 https://doi.org/10.1038/s41559-018-0500-Z

\section{References}

1. Pyron, R. A. We don't need to save endangered species. Extinction is part of evolution. The Washington Post (22 November 2017).

2. Claramunt, S. Extinction, macroevolution, and biodiversity conservation. https://sites.google.com/site/sclaramuntuy/blog/ extinctionmacroevolutionandbiodiversityconservation (2017).

3. Tucker, C. Of course we need to save endangered species: a response. The EEB \& Flow http://evol-eco.blogspot.se/2017/11/ of-course-we-need-to-save-endangered.html (2017).

4. Atkins, J. Saving species from ourselves. PLoS Ecology Community Blog http://blogs.plos.org/ecology/2017/12/01/saving-speciesfrom-ourselves (2017).

5. Schimel, J. Do species matter: responding to an op-ed by R. A. Pyron in the Washington Post as a piece of writing. Writing Science https://schimelwritingscience.wordpress.com/2017/11/30/ do-species-matter-responding-to-an-op-ed-by-r-a-pyron-in-thewashington-post-as-a-piece-of-writing (2017).

6. Antonelli, A. \& Perrigo, A. We must protect biodiversity. The Washington Post (15 December 2017).

7. Dee, L. E., De Lara, M., Costello, C. \& Gaines, S. D. Ecol. Lett. 20, 935-946 (2017).

8. Díaz, S. et al. Science 359, 270-272 (2018).

9. Gross, N. et al. Nat. Ecol. Evol. 1, 0132 (2017).

10. Mora, C., Tittensor, D. P., Adl, S., Simpson, A. G. B. \& Worm, B. PLoS Biol. 9, e1001127 (2011).

11. Sarkar, S. \& Frank, D. M. Nat. Educ. Knowl. 3, 3 (2012).

12. Norton, B. Why Preserve Natural Variety? (Princeton Univ. Press, Princeton, 1987).

\section{Acknowledgements}

We thank E. O. Wilson for discussing this correspondence with us and providing insightful comments and support, V. Herrera, J. Uddling and J. Sandberg for constructive suggestions, and the thousands of scientists and citizens who have signed our petition on www.protect-biodiversity. com and engaged in this discussion.

Competing interests

The authors declare no competing interests. 